\title{
A Study of Wildfire Ignition by Rifle Bullets
}

\author{
Mark A. Finney and Sara S. McAllister*, Missoula Fire Sciences Laboratory, \\ USDA Forest Service, 5775 W US Highway 10, Missoula, MT 59808, \\ $U S A$
}

Trevor B. Maynard, San Dimas Technology and Development Center, USDA Forest Service, San Dimas, CA, USA

Ian J. Grob, Missoula Technology and Development Center, USDA Forest Service, Missoula, MT, USA

Received: 10 February 2015/Accepted: 3 July 2015

\begin{abstract}
Experiments were conducted to examine the potential for rifle bullets to ignite organic matter after impacting a hard surface. The tests were performed using a variety of common cartridges $(7.62 \times 51$ [.308 Winchester (The use of tradenames is provided for informational purposes only and does not constitute an endorsement by the U.S. Department of Agriculture.)], $7.62 \times 39,7.62 \times 54 \mathrm{R}$, and $5.56 \times 45[.223$ Remington]) and bullet materials (steel core, lead core, solid copper, steel jacket, and copper jacket). Bullets were fired at a steel plate that deflected fragments downward into a collection box containing oven-dried peat moss. We found that bullets could reliably cause ignitions, specifically those containing steel components (core or jacket) and those made of solid copper. Lead core-copper jacketed bullets caused one ignition in these tests. Thermal infra-red video and temperature sensitive paints suggested that the temperature of bullet fragments could exceed $800^{\circ} \mathrm{C}$. Bullet fragments collected from a water tank were larger for solid copper and steel core/jacketed bullets than for lead core bullets, which also facilitate ignition. Physical processes are reviewed with the conclusion that kinetic energy of bullets is transformed to thermal energy by plastic deformation and fracturing of bullets because of the high-strain rates during impact. Fragments cool rapidly but can ignite organic matter, particularly fine material, if very dry and close to the impact site.
\end{abstract}

Keywords: Ignition, Hot particles, Rifle bullets, Ballistic impact, Smoldering

\section{Introduction}

In the United States, outdoor target shooting has been suspected as the source of numerous wildland fires [1, 2]. Anecdotally, the ammunition involved in most incidents is thought to be of ordinary commercial varieties with bullets composed of

* Correspondence should be addressed to: Sara S. McAllister, E-mail: smcallister@fs.fed.us

This manuscript was written and prepared by a U.S. Government employee on official time and therefore is in the public domain and not subject to copyright. The use of tradenames is provided for informational purposes only and does not constitute an endorsement by the U.S. Department of Agriculture. 
inert materials including lead, steel, and copper. No scientific studies to date have specifically addressed projectile behavior or properties related to ignition of wildland vegetation or organic material. Thus, the primary focus of this study is whether inert projectiles fired from commonly available modern firearms can cause ignition of wildland vegetal matter.

The possible mechanism by which inert projectiles could cause ignitions involves the conversion of kinetic energy to thermal energy at impact with a solid object or target. In general, pistol cartridges are designed to propel a bullet much slower with less energy than rifle cartridges. Table 1 indicates approximate muzzle energy for a variety of different cartridges. Rifle bullets should thus be the most likely to have sufficient energy for ignition, and will thus be the focus of the study.

Because modern rifle bullets are accelerated to high velocities, they are typically covered with a thin layer of a protective metal, called a jacket. All rounds used in this study used steel or copper jackets. In general, depending on their intended use, bullets may be designed to achieve immediate expansion within the target (expanding bullets, such as for hunting) or penetration through the target (armorpiercing rounds). Armor-piercing rounds typically contain a penetrator constructed of steel or another high density metal. The jacket is destroyed on impact, but the penetrator's momentum propels it into the target substrate. These different bullet designs are incorporated into the study.

Ballistic impact has been researched extensively but has been directed principally toward understanding penetration or perforation of target materials. For a particular target, projectiles of a given speed will perforate it at higher angles (closer to normal) and ricochet at lower angles (more oblique) [3, 4]. The consequences of such impacts most pertinent to ignition are where the impact: (1) converts a large fraction of kinetic energy to thermal energy, (2) fractures the bullet or target into pieces large enough to ignite organic matter, and (3) ejects hot material into the organic matter. We reasoned that these conditions should occur most commonly with oblique impacts on a highly resistant target (no penetration or perforation). The target used in this study is a steel plate angled $20^{\circ}$ to $80^{\circ}$ from horizontal.

Because the heating required to initiate smoldering combustion is considerably lower than flaming combustion and smoldering can transition to flaming combus-

\section{Table 1}

Typical Velocity and Kinetic Energy of Common Small Arms Cartridges [6]

\begin{tabular}{llccr}
\hline Cartridge & Typical firearm used & Weight $(\mathrm{g})$ & $\begin{array}{c}\text { Muzzle } \\
\text { velocity (m/s) }\end{array}$ & $\begin{array}{c}\text { Kinetic } \\
\text { energy (J) }\end{array}$ \\
\hline $.22 \mathrm{LR}$ & 22 rifle & 3 & 361 & 195 \\
$.45 \mathrm{ACP}$ & M1911 Semi-automatic & 15 & 270 & 547 \\
& pistol & 4 & 920 & 1693 \\
$5.56 \times 45$ mm NATO & M-16 rifle & 9 & 840 & 3175 \\
$7.62 \times 51$ mm NATO & M-14 rifle & 43 & 850 & 15,533 \\
\hline $50 \mathrm{BMG}$ & M2 heavy machine gun & &
\end{tabular}


tion when conditions change (creating a "hazardous shortcut to flaming fires" [5]), a smoldering ignition is considered as much of a concern as direct flaming ignition in this study.

\section{Background}

As in-barrel and aerodynamic heating are negligible in terms of bullet temperature increase, the primary source of heating is interaction between the bullet and target. The mechanics of this energy dissipation depend on target and bullet construction. A resilient target, such as the steel plate used in this study and other commonly used targets, requires a large amount of energy to become deformed. The majority of the kinetic energy of the bullet will thus be used to plastically (irreversibly) deform the bullet. For most metals, almost all energy conversion during high strain-rate deformation is manifest as heat [7-9], and because very little heat is lost during the process, many investigators consider the deformation to be adiabatic. No empirical studies of bullet fragment temperatures have been found, but numerical experiments have shown temperature at the impact interface to increase with velocity $[8,10]$. At velocities comparable to rifle bullets $(700 \mathrm{~m} / \mathrm{s}$ to $1000 \mathrm{~m} / \mathrm{s}$ ) (Table 1), modeled temperatures of impact surfaces exceed $500^{\circ} \mathrm{C}[8$, 10].

With sufficient impact velocity and target rigidity, the bullet may fail structurally with only minimal penetration into the target. Xiao et al. [11] identified four distinct deformation and failure modes for blunt-shaped steel $(38 \mathrm{CrSi})$ projectiles fired at rigid steel plates. The first mechanism, mushrooming, occurred at relatively low velocities $(150 \mathrm{~m} / \mathrm{s}$ to $250 \mathrm{~m} / \mathrm{s})$ and was characterized by the radial expansion at the nose of the projectile, leading to a mushroom-shaped appearance, but not causing fracture. As impact velocity increased, the second failure mode, shear cracking, became evident. The mushrooming effect causes stresses to be localized in the head of the projectile, which can lead to cracks that begin at the impact face and propagate backwards. Of significance in Xiao et al. [11] experiments was the bluish discoloration (oxidation) at the head and cracked interface of the projectile, indicating significant heating. For plain carbon steels, this occurs at $255^{\circ} \mathrm{C}$ to $320^{\circ} \mathrm{C}$ [12].

After shear cracking, the failure modes observed by Xiao et al. [11] were dependent on material hardness. Softer projectiles experienced petalling. Petalling is an extension of shear cracking but occurs at higher velocity. The shear cracks propagate even farther rearward, giving the projectile a petalled appearance. Significant discoloration of the petals was evident over much of their length, indicating sustained high temperatures during deformation. Hard projectiles experienced fragmentation - the projectiles shattered into many pieces. The number of fragments increased with projectile velocity. Fragments had some surface discoloration, but it was less prevalent than with the softer petalled projectiles.

Once hot particles are generated, the next step in the process is the ignition. However, ignition by contact with hot particles is not well understood [13]. There are relatively few well-controlled experimental studies examining this mode of 
ignition and even fewer practical theoretical models. Based on what little research has been done in this area, however, a few general trends have been noted. In general, the hot particle must be at a substantially higher temperature than the ignition temperature measured under radiant or convective heating [14-16]. Additionally, higher temperatures are required to initiate both smoldering and flaming ignition as the particle size decreases [16-22]. By performing experiments with steel and aluminum ball bearings in conjunction with a theoretical model, Gol'dshleger et al. [20] showed that increasing the conductivity of the hot particle lowered the required particle temperature. Studies with firebrands indicate that a higher flux of particles will increase the probability of ignition [23]. Increasing the moisture content of both sawdust and pine needle beds has been shown to increase the required particle temperature [16] and thus decrease the ignition probability [24]. The density or physical structure of the receptive fuel was also shown to influence the probability of ignition, with fluffy cotton much easier to ignite than tightly woven cotton [25].

As a worse-case scenario, dry fluffy commercially available peat moss was chosen in this study as the receptive material. The density, moisture content, and mineral (or ash) content of peat has been shown to affect its ignitability. In general, it is more difficult to ignite peat when the density or moisture content increases [26, 27]. However, the minimum ignition energy of Russian peat was shown by Grishin and others [27] to have an optimum level of both density and moisture content. For the lowest density tested $\left(0.38 \times 10^{3} \mathrm{~kg} / \mathrm{m}^{3}\right)$, an increase in the ignition energy was seen. A similar increase in ignition energy was seen with extremely low values of moisture content $(<1 \% \mathrm{MC})$. The combined effect of mineral content and moisture content was examined by Frandsen [28, 29] where it was shown that as the mineral content increases the maximum moisture content for ignition decreases.

\section{Theoretical Model}

As a first approximation, the maximum temperature rise due to impact can be estimated by assuming that all kinetic energy is converted into plastic deformation heating. This approximation is crude and will yield an overestimate of temperature rise, since energy is also dissipated by other mechanisms (sound/pressure waves, fragmentation, deformation and heating of the target). By equating the kinetic energy to the change in internal energy, a simplified estimate of temperature rise is given by:

$$
\Delta T=\frac{v^{2}}{2 c}
$$

where $\Delta T$ is the increase in temperature $(\mathrm{K}), v$ is the velocity of the projectile $(\mathrm{m} /$ $\mathrm{s})$, and $c(\mathrm{~J} / \mathrm{kg} \mathrm{K})$ is the specific heat. Of significance in Eq. 1 is the lack of dependence of temperature rise on mass. In our experiments, all bullets deformed to the point of fracture, resulting in individual fragments rather than a single mass. All 
the heating was assumed due to plastic deformation that occurred prior to fragmentation. Assuming the bullet was a uniform temperature throughout just prior to fragmentation, all the fragments should be the same temperature and equal to the temperature of the whole.

The temperature rises predicted by Eq. 1 for monolithic projectiles of lead, copper, and steel are shown in Figure 1. The specific heats were calculated using the specific heat at the midpoint of ambient and final temperature (determined using an iterative procedure). As an example, the velocity of a Winchester $7.62 \times 54 \mathrm{R}$ 180 -grain soft point bullet is approximately $750 \mathrm{~m} / \mathrm{s}$, which yields temperature increases of $2233^{\circ} \mathrm{C}, 660^{\circ} \mathrm{C}$, and $502^{\circ} \mathrm{C}$ for lead, copper, and steel projectiles, respectively. One method of validating this prediction is by observing the condition of recovered fragments. Lead melts near $320^{\circ} \mathrm{C}$, copper near $1100^{\circ} \mathrm{C}$, and carbon steels between $1400^{\circ} \mathrm{C}$ and $1500^{\circ} \mathrm{C}$. Some lead fragments recovered during our experiments appeared to have melted and re-solidified, but this was not evident for any copper or steel fragments. This observation, though rudimentary, is in agreement with the calculated values.

The simple model described above does not account for the mechanical properties of materials subject to impact loading. The amount of heating caused by plastic deformation depends on strain rate, the type of loading, and the material itself. Currently, there is no accepted theoretical model that completely describes the

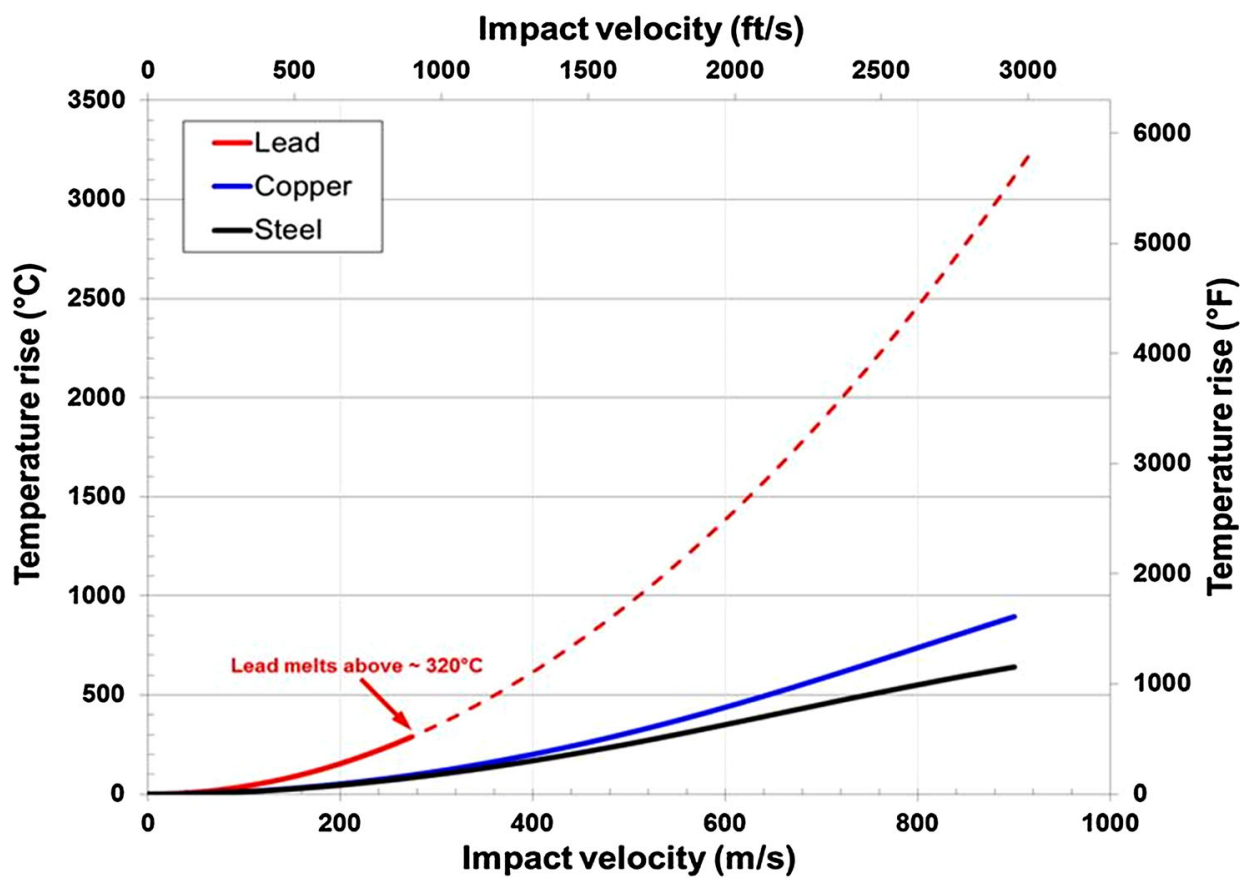

Figure 1. Temperature rise versus impact velocity for an idealized projectile impact (Eq. 1 ). 
heating of objects as they undergo plastic deformation. Though dynamic stressstrain data are limited for high strain rate experiments (due to the difficulty of measurement), we can make some qualitative arguments about the effect of different materials. Brittle materials have limited ductility and do not undergo much plastic deformation before fracturing, while very ductile materials (like copper) can experience significant plastic deformation [30] which should result in a greater temperature rise.

After impact, fragments are reflected from the target surface and travel some distance before reaching the ground. During flight, fragments will lose heat through convective and radiative heat transfer to the surroundings. A simple calculation shows that the radiation heat losses are negligible compared to the convective heat losses. Though their time of flight was not measured, high speed video indicated that fragments in our experiments were airborne for only a fraction of a second before landing on the surface. To estimate the effect of heat loss during this time, the particles are considered thermally thin [31] and treated as circular cylinders in cross flow [32]. Determining the Reynolds number requires the ricochet velocity be known. Experimental data on the ricochet velocity of fragments is scarce, primarily due to the difficulty of measurement. However, intuition leads us to expect that it will be proportional to the impact velocity. Using the initial fragment temperatures obtained by Eq. 1, and assuming cylindrical fragments with a ricochet velocity of $50 \%$ of the impact velocity, the time required to reach $275^{\circ} \mathrm{C}$ (fragments below this temperature would be unlikely to act as ignition pilots) is shown in Table 2 . Since even very small fragments take more than $0.1 \mathrm{~s}$ to cool to $275^{\circ} \mathrm{C}$, it seems likely that fragments reach the ground at temperatures high enough to transfer significant amounts of heat to the surface, particularly because fragments would require only $0.0025 \mathrm{~s}$ at $400 \mathrm{~m} / \mathrm{s}$ to travel approximately $1 \mathrm{~m}$ between impact and resting position in our experimental apparatus.

\section{Table 2 \\ Time Required for a Thermally-Thin Cylindrical Fragment to Reach $275^{\circ} \mathrm{C}$}

Time to reach $275^{\circ} \mathrm{C}(\mathrm{s})$

\begin{tabular}{cccc}
\cline { 2 - 3 } Diameter $(\mathrm{cm})$ & Length/diameter & Steel $\left(\mathrm{T}_{\mathrm{i}}=614^{\circ} \mathrm{C}\right)$ & Copper $\left(\mathrm{T}_{\mathrm{i}}=767^{\circ} \mathrm{C}\right)$ \\
\hline 0.5 & 0.09 & 0.12 \\
& 0.25 & 0.18 & 0.23 \\
0.5 & 0.28 & 0.35 \\
1.0 & 0.37 & 0.46 \\
1.5 & 0.55 & 0.69 \\
2.0 & 0.73 & 0.92 \\
3.0 & 1.10 & 1.38 \\
5.0 & 1.84 & 2.31 \\
\hline
\end{tabular}




\section{Experimental Methods}

The study was designed to principally evaluate effects of bullet construction on ignition by bullet fragments themselves (not pieces of the target). Different calibers were used because these varied the velocity and bullet mass as well as constituent materials. Cartridges selected were based on the availability to the general public and the variety of bullet materials available (Table 3; Figure 2). Steel core ammunition was only widely obtainable for the $7.62 \times 54 \mathrm{R}$ and the $5.56 \times 45$. Ammunition with steel jacketed bullets (referred to as Bi-metal) has thin copper gilding on the outside surface but is mostly made of soft steel. Copper jacketed and lead core bullets are the most common and come in many brands and varieties of jacket style.

The target used for most tests was a steel bullet trap consisting of a deflector and a collector box (Figure 3a). The deflector was a $1.91 \mathrm{~cm}$ thick Abrasion Resistant (AR-500) steel plate $0.91 \mathrm{~m}$ wide by $1.22 \mathrm{~m}$ long. The bottom edge of the deflector was connected by a hinge to the middle of the rim of a collector box with dimensions $0.91 \mathrm{~m}$ by $1.52 \mathrm{~m}$ by $0.3 \mathrm{~m}$ made of $0.64 \mathrm{~cm}$ thick soft steel. The hinge allowed the deflector angle to be adjusted between 0 and 90 from horizontal by means of a cable and winch. Angle-iron was bolted to the edges of the deflector to redirect fragments into the collector.

Shooting took place in the laboratory from a distance of about $32 \mathrm{~m}$. The sound from the muzzle blast was lessened by use of an external plywood suppressor box $(0.91 \mathrm{~m} \times 0.91 \mathrm{~m} \times 1.21 \mathrm{~m})$ fitted with internal vertical plywood baffles spaced $15 \mathrm{~cm}$ apart and covered by carpet on both fore and aft surfaces. The muzzle of the rifle was inserted into a rectangular hole $(7.5 \mathrm{~cm}$ horizontal by $15 \mathrm{~cm}$ vertical) cut through the baffles to allow sighting of the target downrange. The bullet trap was housed inside a plywood shell to prevent fragments from damaging cameras or laboratory equipment (Figure 3b). Further details and photographs of the apparatus can be found in [33]. The following tests were conducted:

- Peat ignition tests on the steel target at combinations of cartridge, bullet type, and deflection angle $\left(20^{\circ}, 30^{\circ}, 40^{\circ}, 60^{\circ}\right.$, and $80^{\circ}$ from horizontal). Five shots fired for each combination.

- Excelsior ignition test (Barnes TSX only). Three shots fired.

- Bullet fragment temperature with empty collector box (IR camera).

- Bullet fragment temperature ("birdhouse" attachment to deflector plate, see Figure 4).

- Bullet fragment size distribution with deflector set to 30 (water filled collector). Two shots fired.

Located immediately downrange of the suppressor box, a chronograph (PACT Professional XP) was used to measure the muzzle velocity of each shot. Most ignition tests were conducted with commercial peat moss that was oven dried at approximately $90^{\circ} \mathrm{C}$ for 2 days and poured into the collector box to a depth of approximately $10 \mathrm{~cm}$. Given the uncontrollability and uncertainty of bullet frag- 


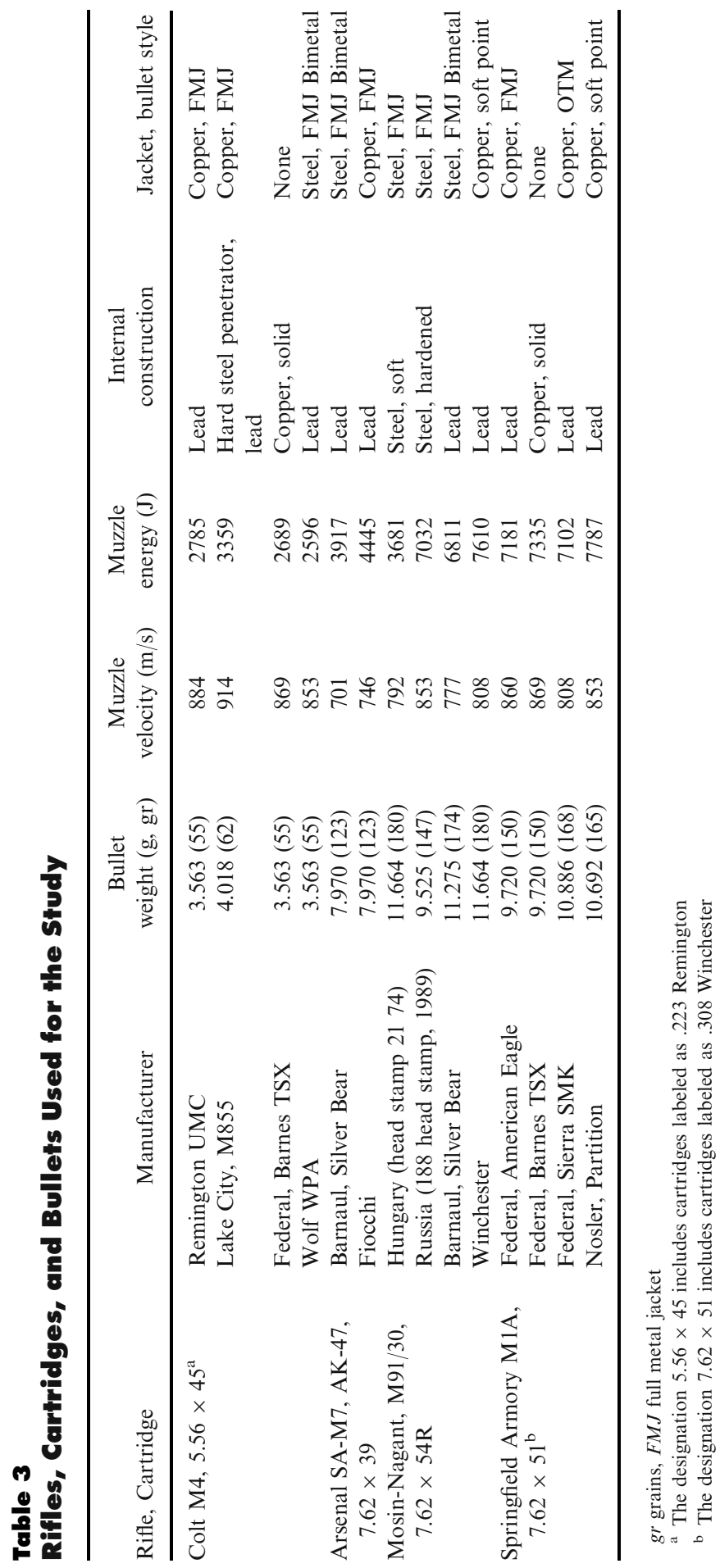




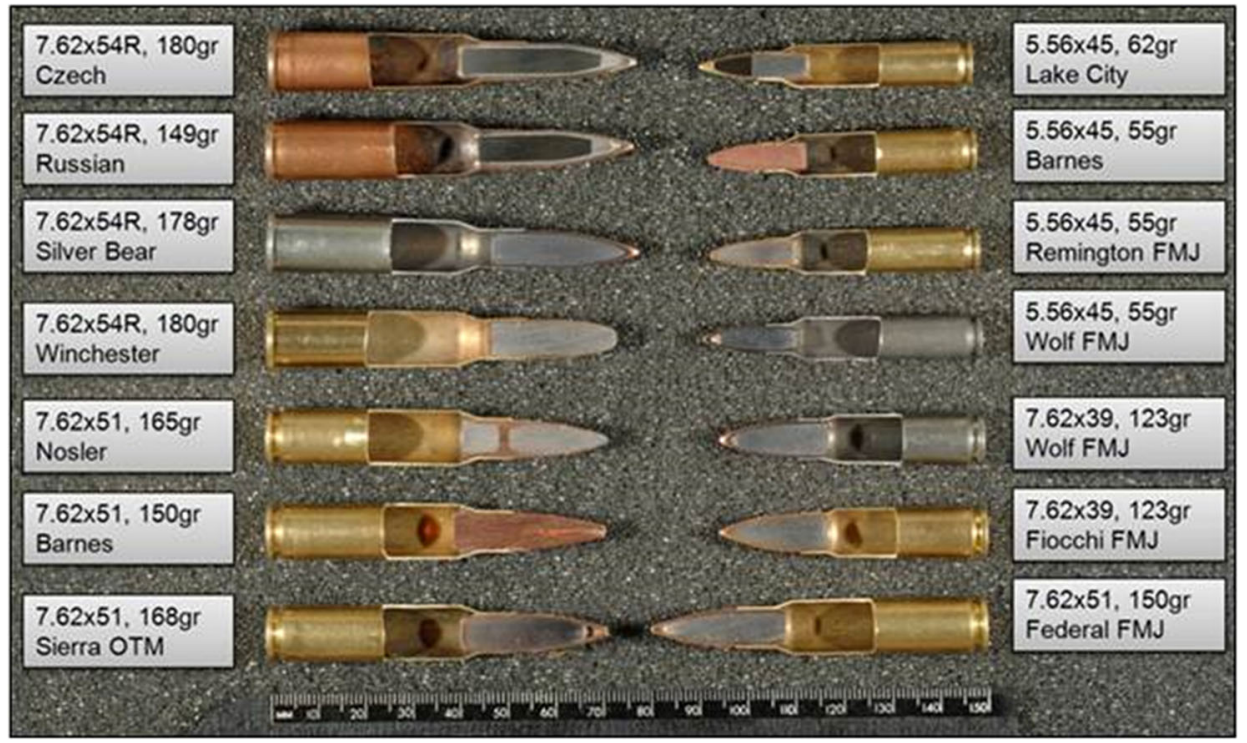

Figure 2. Cross-sections of bullets used in this study. Photograph by J. Kaułz.
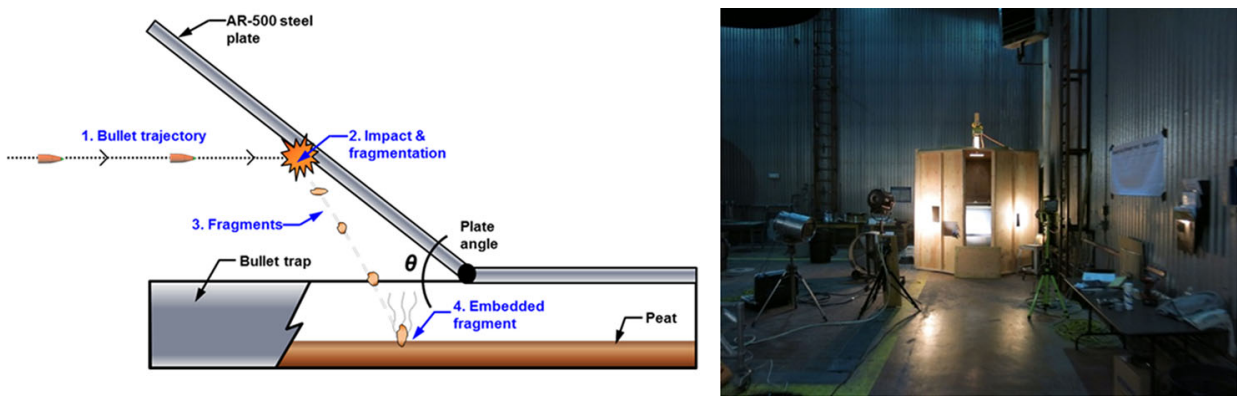

Figure 3. (a) Sketch of the bullet trap designed with an angle-adjustable deflector plate mounted in the middle of a steel collector box for bullet fragments deflected downward after impact, (b) photograph shows the bullet trap and white deflector plate visible between the doors of a plywood shell with cutouts for cameras and lighting.

ment properties (velocity, size, temperature, etc.), an ignition-sensitive material such as peat was thought necessary to allow ignition differences between bullet types to be distinguished. In other words, if ignitions were very rare, our limited set of tests may not be able to detect ignitions or make comparison among bullet materials. Peat was chosen because it is a partially decomposed organic substance similar to upper soil layers with large fractions of incorporated organic material. The ground surface would be a likely resting location for bullet fragments. Also, 

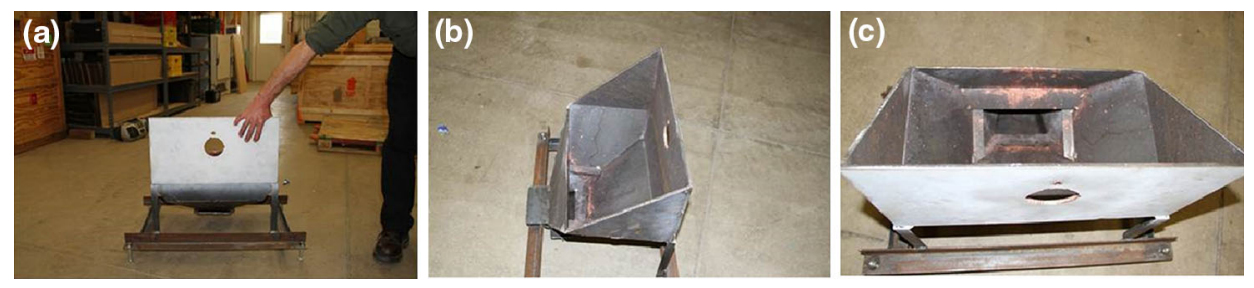

\section{Figure 4. Photographs of the "birdhouse"" attachment to the deflec- tor plate on the bullet trap that allowed collecting and concentrating fragments onto plates painted with temperature sensitive paints.}

peat is composed of fine particles that would increase surface contact with small bullet fragments.

Dryness of the peat became an important factor, so controls were put in place to maintain moisture conditions of the peat. The dryness of the peat was maintained after removing it from the drying oven by heating the collector box underneath with heat tape and aiming halogen heat lamps along the sides. Measured temperatures of the box remained at approximately $55^{\circ} \mathrm{C}$, similar to soil surface temperatures on sunny summer days. The environment of the laboratory was sustained at temperatures of $38^{\circ} \mathrm{C}$ to $43^{\circ} \mathrm{C}$ and approximately $7 \%$ to $10 \%$ relative humidity. This preserved moisture content of the peat between $3.0 \%$ and $4.5 \%$ (dry weight basis). Moisture sampling of the peat was performed approximately every $15 \mathrm{~min}$ to $30 \mathrm{~min}$ using a Computrac MAX 2000XL automatic balance.

Ignitions were recorded after shooting each set of bullets by first observing the peat for smoldering spots. When observed, each spot was excavated with a small trowel to remove it from the collector before the ignition spread throughout the box. The volume of peat containing the smoldering spot was sifted on the pavement to attempt to find the fragment responsible. The number of smoldering spots was counted for each set of shots ("Appendix" section) and once all visible ignitions had been removed, the trowels were used to thoroughly overturn the peat in the collector box in preparation for subsequent tests. We noted that it often took several minutes before all ignitions were found-some being buried near the bottom of the peat. Once satisfied that no residual burning material was present, the next series of bullets was fired.

Measurement of bullet fragment temperatures was attempted by remote methods using a calibrated thermal IR video camera (Cincinnati TVS-8500) and directly by use of temperature sensitive paints. To capture IR images, the bullet collector box was emptied and the camera aimed to focus on the bottom surface with the deflector angle set to $30^{\circ}$ from horizontal. IR video taken at $30 \mathrm{fps}$ was analyzed by tabulating maximum temperature of the pixels in the image over time to obtain cooling rates. The direct measurement of the approximate fragment temperature was attempted using a "birdhouse" attachment to the deflector/collector (Figure 3). The bullet was fired through the $7.6 \mathrm{~cm}$ hole in the front plate. Fragments were contained inside the birdhouse and ricocheted off a series of baffles arranged to indirectly funnel them downward to rest upon a steel plate $(0.16 \mathrm{~cm}$ thick $)$ coated with a 
temperature sensitive paint. Two tests were conducted at each paint temperature $\left(300^{\circ} \mathrm{C}, 400^{\circ} \mathrm{C}, 500^{\circ} \mathrm{C}, 600^{\circ} \mathrm{C}, 700^{\circ} \mathrm{C}, 800^{\circ} \mathrm{C}\right)$ consisting of a single shot of $7.62 \times 51$ Barnes TSX. This bullet and cartridge was selected because ignitions consistently resulted during the peat tests and the fragments were not as damaging to the apparatus as steel-core bullets, which also readily produced ignitions.

Video in the visible portion of the spectrum was recorded for bullet impacts with a Photron Apex high speed video camera. Various recording rates were used, ranging from $8000 \mathrm{fps}$ to $100,000 \mathrm{fps}$, to attempt to capture impact fragmentation and impact flash. The various recording speeds were a result of the trade-off between resolution, aperture (for depth of field), and frame rate.

We statistically examined the pairwise relationship between cartridge type and both ignition occurrence and number of ignitions via the Bonferroni method [34] and the less conservative Tukey's HSD test. In no case was there a statistically significant difference in the effect of cartridge types. We then examined the relationship between other predictors and ignition response via the use of Generalized Linear Mixed Modeling (GLMM) Poisson regression. The purpose of the regression analysis was to distinguish and characterize responses rather than to produce a predictive model since the data collected reflect the particulars of the laboratory testing such as number of shots and target distance. Although the number of separate ignitions in each set was recorded, the GLMM used only the binary responses of ignition or no-ignition. The dummy variables of bullet core material (lead, steel, copper) and jacket material (steel, copper) were specified in the model.

\section{Resulfs}

A total of 433 rounds were fired against the steel target. The impact of rifle bullets consistently produced ignitions in dry peat, especially for the solid copper and steel core/steel jacketed bullets (for a full table of results, see "Appendix" section). Ignitions were detected visibly as smoldering spots in the peat. Sometimes several separate ignitions were produced from the multiple fragments produced for a particular test (5 shots). Sometimes several minutes went by before all ignitions were detected. This was interpreted as a function of the depth that a hot fragment was buried in the peat layer which required time for the ignition or smoke to become visible. A single test for ignition of dry excelsior by the solid copper bullets ( 3 bullets) produced ignitions.

Fragments found by excavating ignitions in the peat suggested that bullet fragments were responsible for the ignition rather than steel eroded from the target. For steel jacketed bullets, very small (only a few millimeters across) fragments of jacket material were often found inside the incipient ignition. Particles of this size have been reported to require temperatures of $1100^{\circ} \mathrm{C}$ or above to cause ignitions in dry cellulose [17]. At low target angles, little cratering of the target occurred regardless of bullet type, limiting alternative sources of hot materials other than bullet fragments themselves. At high target angles using bullets with hardened steel penetrators, cratering of the steel target could have liberated steel fragments and contributed to the ignitions. The process of deformation and fragmentation of the target would produce hot particles in the same way as discussed for bullet 


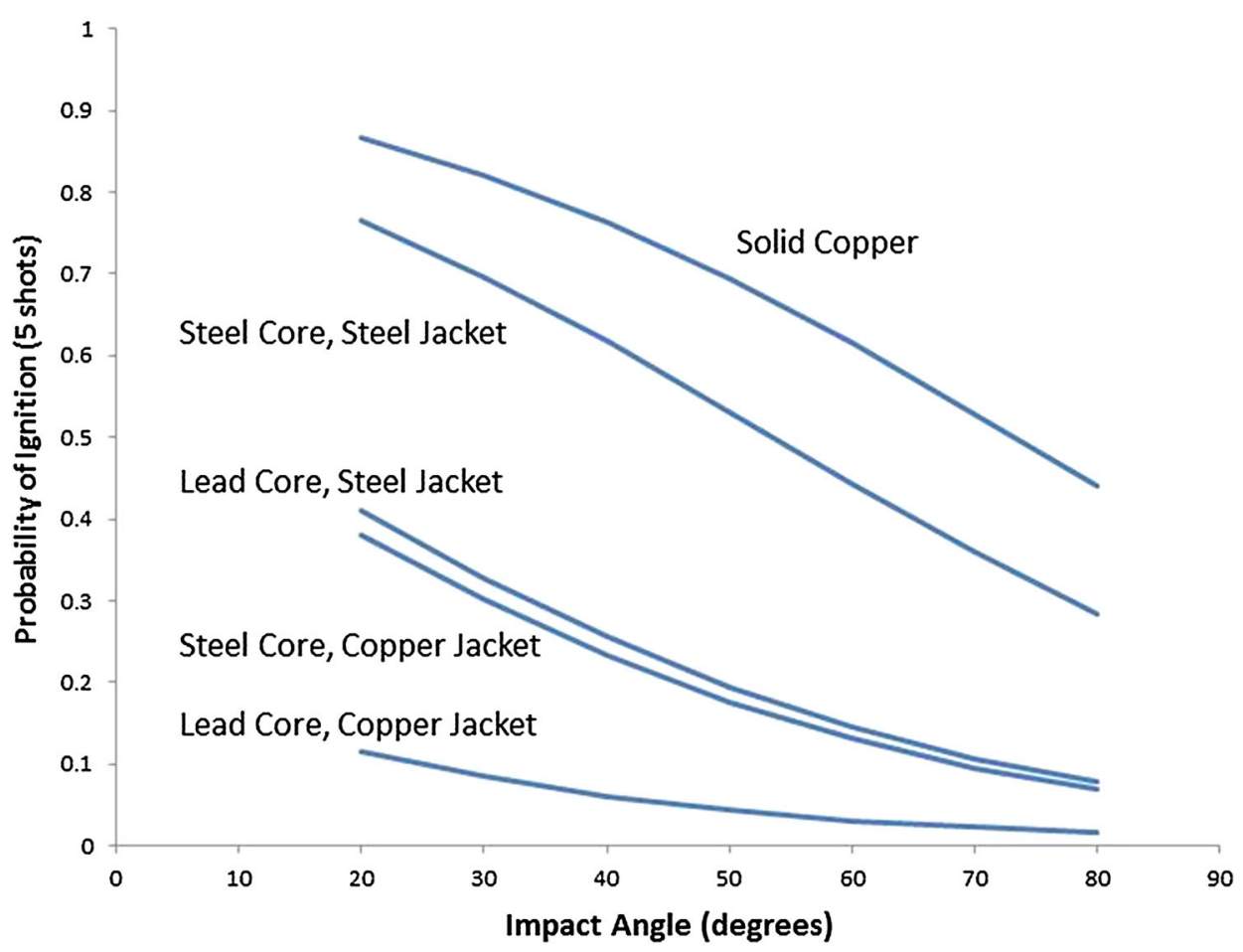

Figure 5. Graph showing statistical regression model of laboratory data on probability of ignition as a function of bullet-type variables. Probability of ignition applies to 5 -shot groups in oven dried peat.

fragments. We did observe in one place where the sharp edge of a crater rim on the target had chipped from subsequent impacts and could have contributed hot material for ignition.

Statistical analysis of the ignition results by Poisson regression revealed significant differences among bullet materials (Figure 5). The regression model (Table 4) represented separately the effects of core material and the jacket material compared to the base model that represented solid copper bullets.

\subsection{Bullet Material}

Bullet construction materials were important factors in producing ignition. The only type of bullet that consistently did not produce ignitions was made with a lead core and copper jacket, although a single ignition was observed from a Nosler partition bullet (see Figure 2). Solid copper bullets were the most consistent in producing ignitions at all angles and all targets. Fragments of the solid copper bullets appeared larger than fragments of other bullet types. Fragments recovered from the water-filled collector box supported this observation with solid copper bullets having the most combined weight of recovered fragments (Figure 6; Table 5). Bullets with lead core and copper jacket produced the smallest frag- 


\section{Table 4}

\section{Regression Estimates for Poisson Model of Ignition Probability as a Function of Bullet Core and Jacket Materials}

\begin{tabular}{lcrl}
\hline Equation \& coefficients & SE & z value & $\operatorname{Pr}(>|z|)$ \\
\hline Ignition probability $=1 /(1+\exp (-(2.57971$ & 0.58514 & 4.409 & $1.04 \mathrm{e}-05$ \\
-3.90678 steelcore -2.35951 Leadcore & 0.66442 & -5.880 & $4.10 \mathrm{e}-09$ \\
-1.66653 steeljacket -0.03522 angle $)))$ & 0.65998 & -3.575 & 0.00035 \\
& 0.57410 & 2.903 & 0.00370 \\
& 0.01209 & -2.912 & 0.00360 \\
\hline
\end{tabular}

Core and jacket variables are set either to zero or one. If both are set to zero then regression produces results for solid copper bullets. All coefficients were statistically significant at least to the 0.001 level

ments with the least recovered weight. Bullets with steel components were found to produce ignitions but not as consistently as the solid copper bullets.

The regression model suggested that impact angle should also play a role in ignition probability, with more oblique angles more likely to produce an ignition. However, when the target was set at higher angles $\left(60^{\circ}\right.$ to $\left.80^{\circ}\right)$ we suspected that more bullet fragments were escaping the collector box. The effect of angle on ignition would, therefore, involve more than effects on fragment properties (size or

\subsection{2×39, 123gr, Lead Core Steel Jacket}

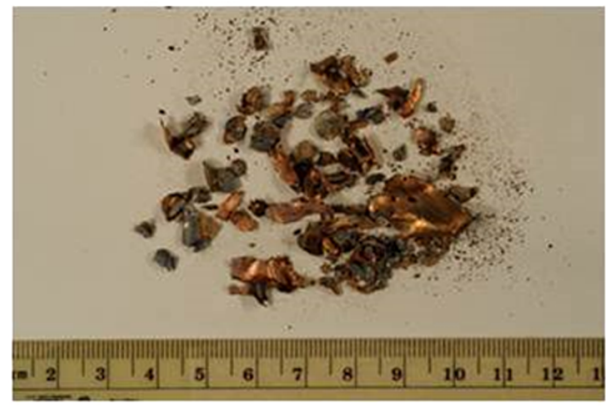

7.62×51, 150gr, Lead Core, Copper Jacket FMJ

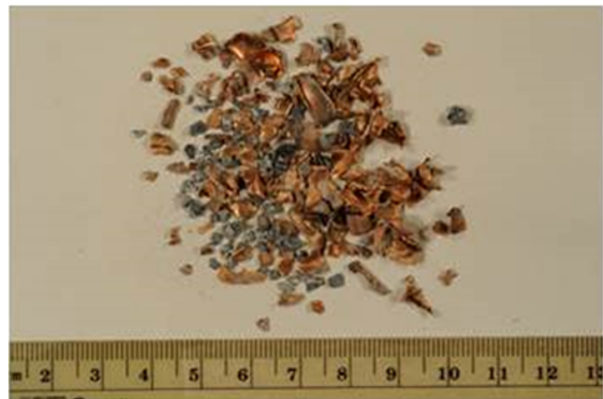

7.62x54R, 149gr, Steel Core, Steel Jacket

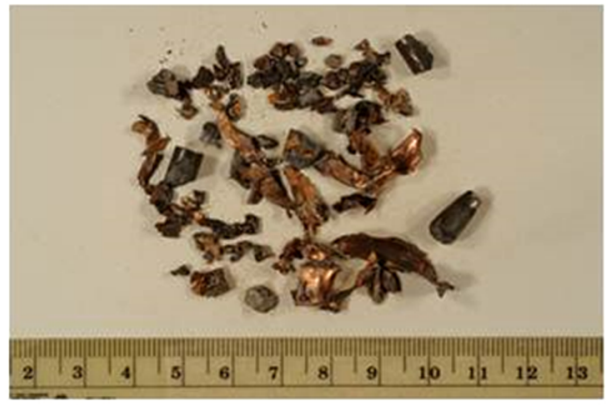

$7.62 \times 51$ 150gr Solid Copper

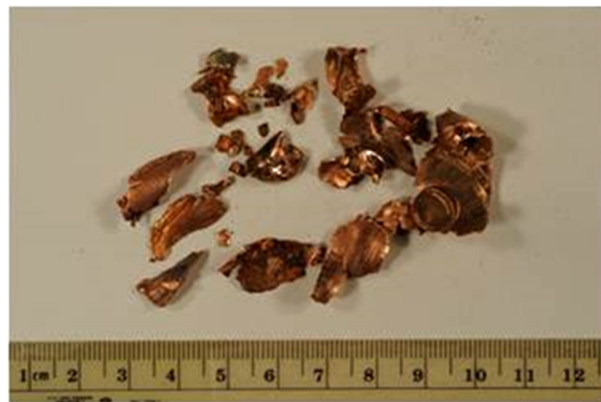

Figure 6. Photographs of bullet fragments collected after impact from water-filled collector tank. 


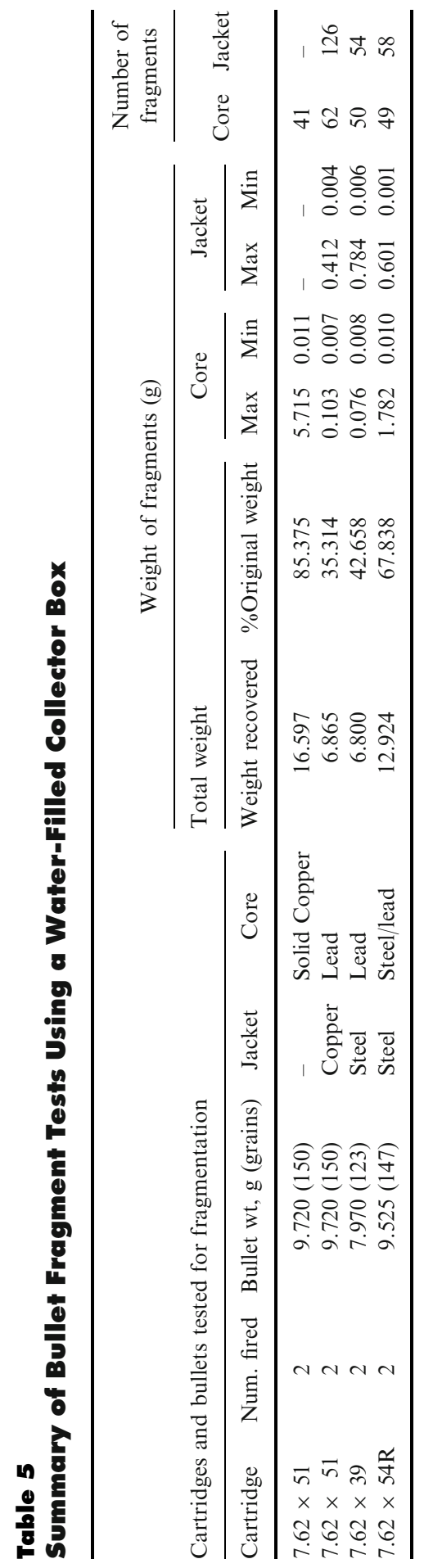




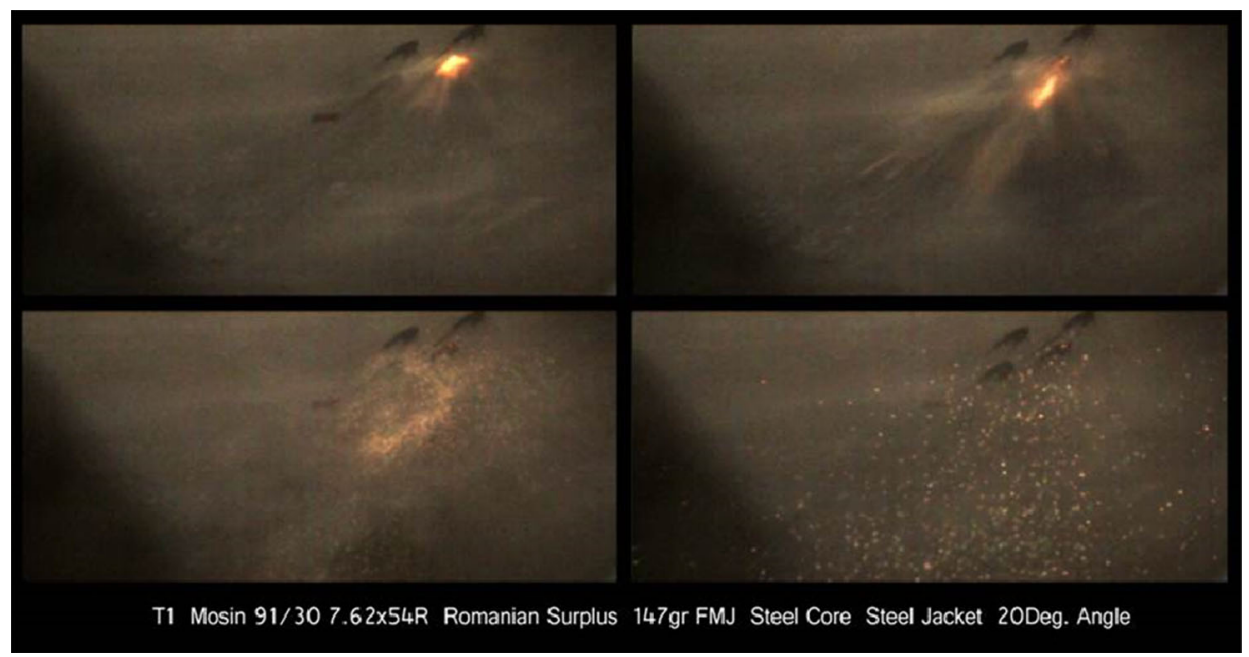

\section{Figure 7. Frame sequence from high speed video $(20,000 \mathrm{fps})$ of $147 \mathrm{~g} 7.62 \times 54 \mathrm{R}$ steel core-steel full metal (steel) jacket bullet impacting steel plate at $20^{\circ}$ angle (from horizontal) shows the "im- pact flash" " produced by oxidation or burning of metal spall and hot glowing particles deflected downward.}

number). At high impact angles, fragments flying farther from the point of impact will experience more cooling before finally resting on potential ignitable substrate (Table 2) and may be less likely to cause ignitions.

High speed video ( $\sim 20,000 \mathrm{fps})$ captured the impact and trajectory of splatter as well as an "impact flash" (Figure 7) that was visible for most bullets. Impact flash is not visible to the naked eye in daylight but is clearly visible in the videos. Bullets having a steel core displayed the greatest and longest-lasting flash. Smaller flash was visible from impact of bullets with lead core and of solid copper. Impact flash has been described as the burning of metal spall (oxidizing metal dust from the target and/or projectile) at temperatures of about $3000 \mathrm{~K}[35,36]$. Its duration is very short and was visible in high speed video for less than $1 / 2000$ th of a second ( $<10$ frames at $\sim 20,000 \mathrm{fps}$ ).

\subsection{Temperatures of Bullet Fragments}

The thermal camera captured $30 \mathrm{fps}$ and recorded the movements and approximate temperatures of the fragments as they bounced around in the collector. Assuming fragment emissivity to be 1.0, the thermal images recorded peak temperatures of $550^{\circ} \mathrm{C}$ to $793^{\circ} \mathrm{C}$. We attribute little significance to the apparent variability among bullets or shots because there was no control over fragment numbers, sizes, or locations in the field of view. Also, for several reasons discussed below, these estimated temperatures must be considered conservative values that may be affected by factors beyond the control of the experiments. Even without confidence in the actual fragment temperature, these data are indicative of high 
thermal energy of the particles and the rapid cooling rates following impact. Higher cooling rates of the steel-components were indicated compared to fragments of the solid copper bullets. The steel components cooled within several seconds to temperatures near the minimum setting for the camera $\left(375^{\circ} \mathrm{C}\right)$ but copper took approximately three times longer. This may be caused by higher initial temperatures or partially a function of the larger sizes of the copper bullet fragments because more rapid cooling of copper (for equivalent mass) would be expected from the higher thermal conductivity compared to steel (almost 10 times greater).

Examination of the temperature-sensitive plates from the "birdhouse" tests revealed discoloration from contact points with hot fragments at all temperature levels, including the maximum of $800^{\circ} \mathrm{C}$. The density of discolored places decreased with increasing temperature threshold for the paints, suggesting that most particles cool too rapidly to discolor the paint or are not raised to higher temperatures initially. Given the single temperature threshold of each paint and the thermal conductivity and limited contact on flat steel plates, these results are necessarily conservative estimates of actual fragment temperature. They are consistent with both the theory and the thermal camera data, which reveal fragment temperatures sufficient for ignition.

\section{Discussion}

No previous studies have been devoted to the particular problem of ignition by metal fragments heated upon ballistic impact. The physical processes and factors involved throughout the sequence of impact, fragmentation, and ignition are, nevertheless, interpretable from studies of related phenomena. In general, high velocity impacts produce heat in the rapidly deformed projectile (and possibly the target) that must quickly come to rest on a dry ignitable material. The rapid cooling of fragments, their small sizes, and odd shapes mean that fine-grained substrates such as peat provide more opportunity for direct contact and ignition. The toughness of different metals determines how much energy is required for deformation and fracturing, and thus, how much heat is generated when the particle material ultimately fails. This is why bullet construction is important to heating and ignition.

Our study focused on laboratory testing of different bullets loaded in commercial ammunition. We observed that bullet material did affect fragment sizes and ignitions, with steel components and solid copper bullets producing the largest fragments and the most likely ignitions in peat. Despite similar maximum temperatures recorded on thermal images, larger fragments from solid copper bullets seem to be the most plausible explanation for the slower rates of temperature decline compared to steel seen in the image sequences. The opposite trend would be expected based only on the greater thermal conductivity of copper than steel, meaning that heat loss rates should be greater for equivalent fragment mass. Both copper and steel are much "tougher" metals compared to lead, meaning that a greater amount of energy is required for plastic deformation at a particular strain rate. Lead therefore deforms with relatively little energy, and due to its relatively low melting temperature, will probably melt. 
The actual bullet fragment temperatures remain unknown, but they are consistent with the physical theory of plastic deformation under high strain rates. Maximum temperatures of about $550^{\circ} \mathrm{C}$ to nearly $800^{\circ} \mathrm{C}$ were recorded on thermal images for several bullet types and were consistent with the discoloration reaction by fragment contact with the temperature-sensitive paints. Both must be considered conservative estimates of the true fragment temperatures because:

(1) The thermal camera was operated at $30 \mathrm{fps}$ and could miss high temperatures of shorter duration.

(2) There is an unknown and uncontrolled ratio of bullet fragment size relative to the pixel area in an image, which can lead to under-representing temperature due to partial pixel coverage by the fragment.

(3) The emissivity of the bullet fragments is not known but assumed to be 1.0 for these calculations and which must therefore underrepresent the actual temperature.

(4) Irregular particle geometry offers few contact points on a flat steel plate for discoloring the paints.

(5) Thermal properties of the steel plate may diminish the paint response to small fragments.

This study intentionally did not address ignition by target material dislodged by the impact. Most ballistic impact studies are concerned with perforation or penetration of the target, often metal, which may break away. Loose pieces of target metal have been fractured by similar deformation physics as described for the projectile, and it is possible that fires could ignite from them as well.

From this study, an understanding of wildfire ignitions from field reports begins to emerge, but also involves other processes not encompassed by this work. The following is a discussion of linkages to field-scale wildfire ignitions, given that the present study was confined to a laboratory apparatus and limited to detection of smoldering ignition very close to the target $(<1 \mathrm{~m})$. First, target materials that are highly resistant to damage would be similar to the steel plate tested here, such as boulders, rocks, or thick metal such as silhouettes. Oblique angles of impact may be important, regardless of target material, to producing larger fragments that would cool more slowly after contacting organic matter. Second, bullet materials clearly affect ignition potential, with steel components and solid copper having the greatest chance of producing hot fragments. We observed only one ignition from lead-core copper jacketed bullets. Third, the very rapid particle cooling means the ignitions are more likely nearer the target. Fragment size distribution was not known or controlled, but smaller pieces cool so quickly that they must contact the suitable substrate very rapidly. The distances from a target that ignitions can occur are not determined by the present study. Fourth, ignitions are observed in the field only when the fire begins to spread. This is probably not when or where ignition actually takes place. The original ignition likely occurs in a material similar to peat, meaning partially decomposed organic matter incorporated in the surface horizons of the soil - not the vegetation or fuel which carries the spreading fire with visible flames. The process of transition from smoldering incipient ignition to spreading fire may take some time (minutes to days, even weeks) depending on the fuel types and the 
weather and fuel conditions. Where the target is exposed to wind, a smoldering ignition in litter or duff may be ventilated easily and ignite grasses or surface litter and become visible more quickly than an area sheltered by trees or terrain.

Consistent with previous research on particle ignition, bullet fragments can be very small and still effective in producing ignitions. The multiple ignitions observed in this experiment from small fragments of a single bullet means that it may be difficult to identify the exact piece of bullet material that causes an ignition under field conditions. The limited testing using dry excelsior revealed that other material besides decayed organic matter can also be ignited by bullet fragments but further testing beyond this study will be required. As with all fire behavior and ignition research, moisture content of the organic material will be an important factor in ignition. Peat moisture contents of $3 \%$ to $5 \%$, air temperatures of $34^{\circ} \mathrm{C}$ to $49^{\circ} \mathrm{C}$, and relative humidity of $7 \%$ to $16 \%$ were necessary to reliably observe ignitions in the experiments. Peat moisture contents above this (perhaps $8 \%$ ) did not produce ignitions. Field conditions matching the experimental range would imply summertime temperatures, as well as solar heating of the ground surface and organic matter to produce a drier and warmer microclimate where bullet fragments are deposited.

\section{Acknowledgments}

Conducting this study depended on the support and ingenuity of many people. Chuck Harding constructed the bullet trap. Jack Kautz, Randy Pryhorocki, and Andrew Gorris built and designed the laboratory shooting range apparatus including external sound suppressor and birdhouse attachment to the deflector. Mark Vosburgh, Amanda Determan, and Dan Jimenez took responsibility for video imagery. Jay Fronden and Jason Forthofer assisted in all phases of the shooting tests. Mike Bonzano ensured range safety for the laboratory tests. Dave Ball of the Missoula County Sheriff's Department graciously helped with the access and use of the outdoor range. Isaac Grenfell provided data processing and statistical advice and analysis. Shari Kappel and Corrie Kegel oversaw safety and security plans for the indoor testing. This report was greatly improved from the review comments provided by Don Latham, Vytensis Babrauskas, Steve Mates, and John Fehr.

\section{Open Access}

This article is distributed under the terms of the Creative Commons Attribution 4.0 International License (http://creativecommons.org/licenses/by/4.0/), which permits unrestricted use, distribution, and reproduction in any medium, provided you give appropriate credit to the original author(s) and the source, provide a link to the Creative Commons license, and indicate if changes were made.

\section{Appendix}

See Table 6. 


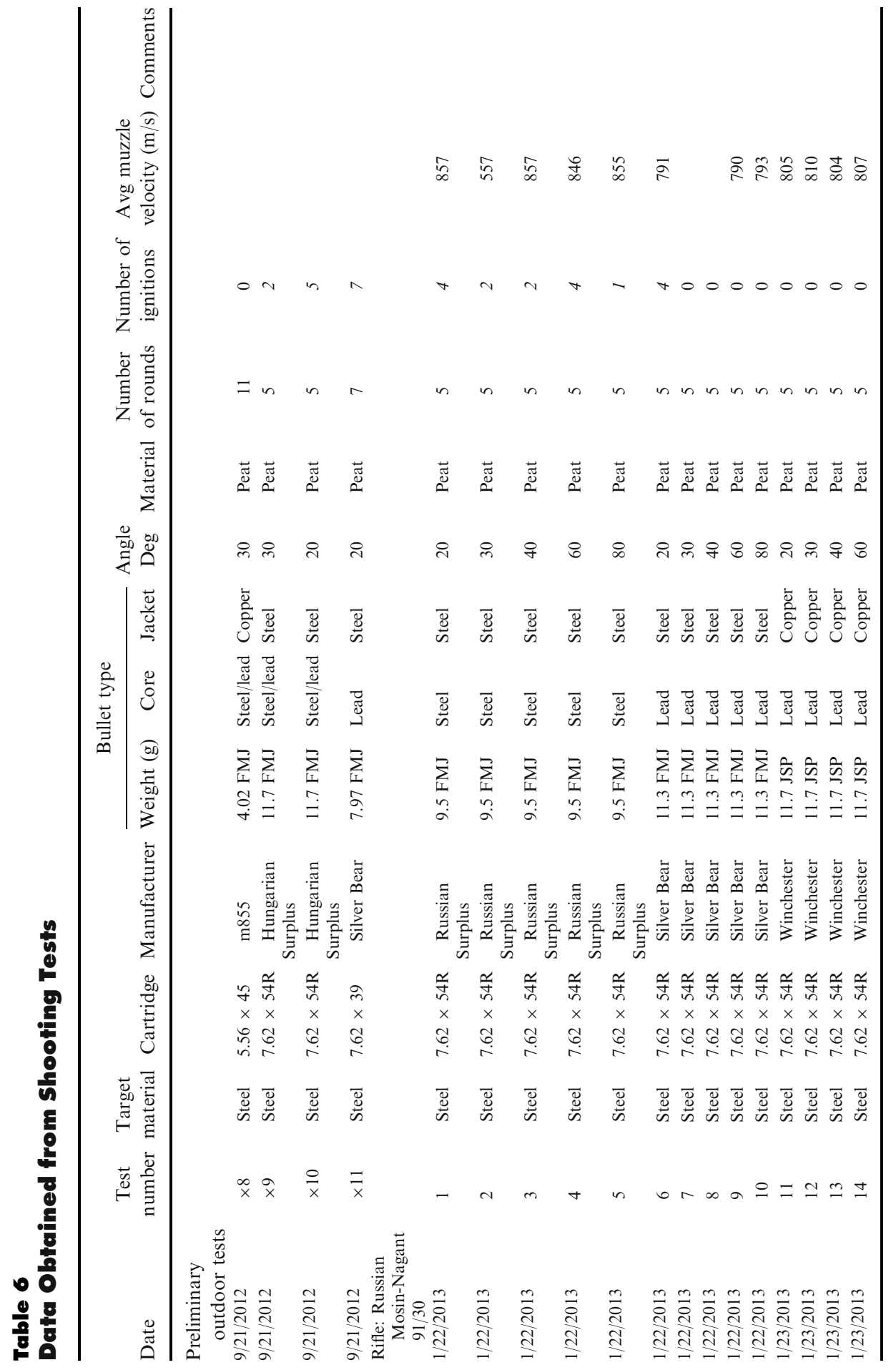




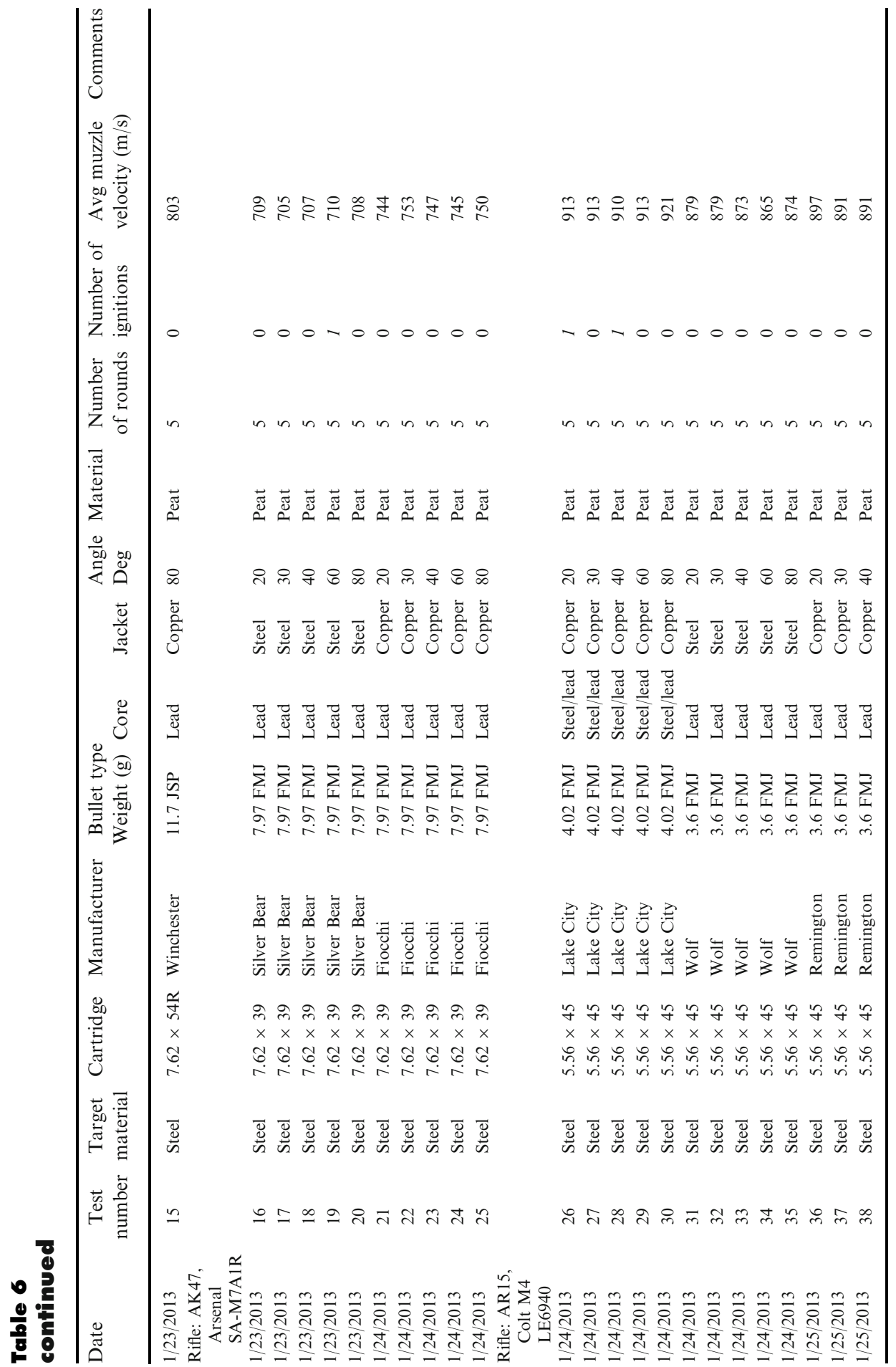




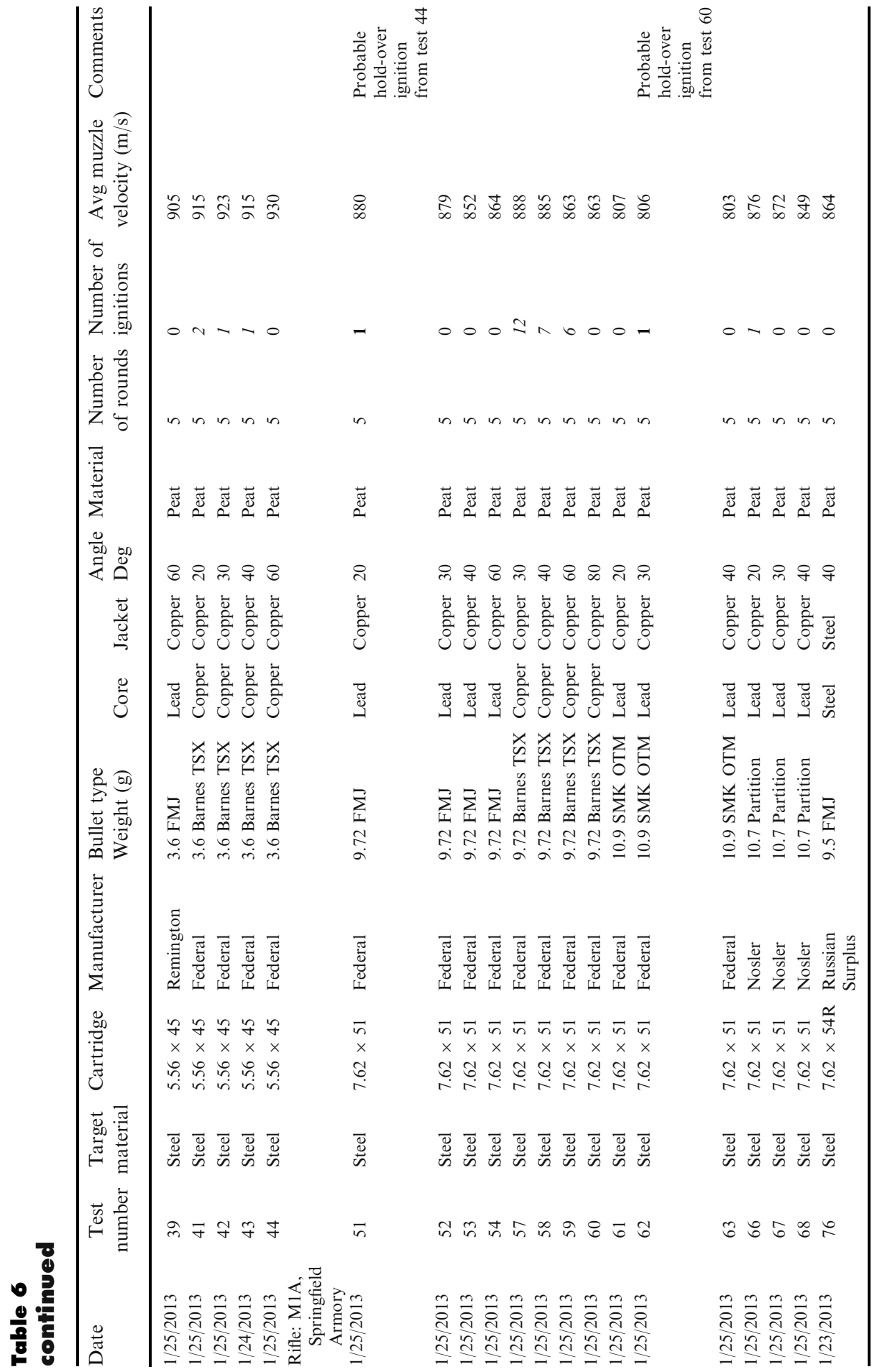




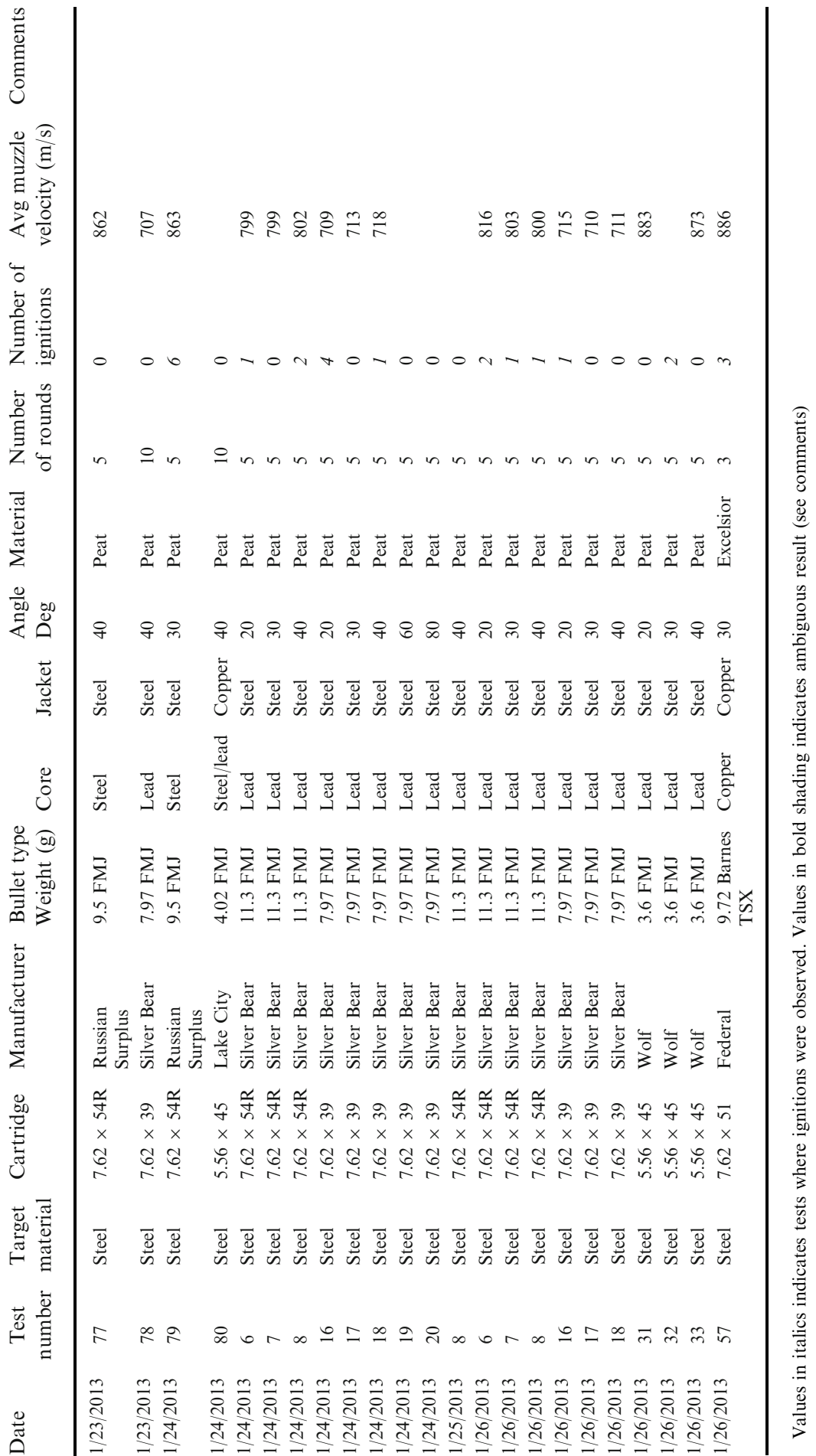




\section{References}

1. Guns blamed for starting some wildfires in the west. CBS News, July 4th, 2012. http://www.cbsnews.com/news/guns-blamed-for-sparking-some-wildfires-in-west/

2. Gunfire blamed for some wildfires; target shooting limited. USA Today, July 3, 2012. http://content.usatoday.com/communities/ondeadline/post/2012/07/gunfire-blamed-forsome-wildfires-states-consider-limits/1\#.UCF4202PXwk

3. Johnson W, Sengpta AK, Ghosh SK (1982) High velocity oblique impact and ricochet mainly of long rod projectiles: an overview. Intl J Mech Sci 24(7):425-436

4. Goldsmith W (1999) Non-ideal projectile impact on targets. Intl J Impact Eng 22:95395

5. Rein G (2009) Smouldering combustion phenomena in science and technology. Int Rev Chem Eng 1:3-18

6. U.S. Army (1994) Army ammunition data sheets: small caliber ammunition-FSC 1305. Technical Manual TM 43-0001-27. Washington, DC: U.S. Government Printing Office. 1994-546-043:80742

7. Rogers HC (1979) Adiabatic plastic deformation. Annu Rev Mater Sci 9(1):283-311

8. Yildirim B, Muftu S, Gouldstone A (2011) Modeling of high velocity impact of spherical particles. Wear 270:703-713

9. Kapoor R, Nemat-Nasser S (1998) Determination of temperature rise during high strain rate deformation. Mech Mater 27(1):1-12

10. Molinari JF, Ortiz M (2002) A study of solid-particle erosion of metallic targets. Intl J Impact Eng 27:447-458

11. Xiao X, Zhang W, Wei G, Mu Z (2010) Effect of projectile hardness on deformation and fracture behavior in the Taylor impact test. Mater Des 31(10):4913-4920

12. Oberg E, Jones FD, Horton HL (1990) Machinery's handbook, 23th edn. Industrial Press, New York

13. Babrauskas V (2003) Ignition handbook (Ch. 7, pp 238-239; Ch. 7, pp 287-289; Ch. 11, pp 500-509; and Ch. 14, pp 842-844). Fire Science Publishers, Issaquah

14. Setchkin NP (1949) A method and apparatus for determining the ignition characteristics of plastics. J Res NBS 43:591-608

15. Kuchta JM, Furno AL, Martindill GH (1969) Flammability of fabrics and other materials in oxygen-enriched atmospheres. Part 1. Ignition temperatures and flame spread rates. Fire Technol 5:203-216. doi:10.1007/BF02591517

16. Tanaka T (1977) On the inflammability of combustible materials by welding spatter. Rep Natl Res Inst Police Sci 30(1):51-58

17. Hadden RM, Scott S, Lautenberger C, Fernandez-Pello AC (2011) Ignition of combustible fuel beds by hot particles: an experimental and theoretical study. Fire Technol 47:341-355. doi:10.1007/s10694-010-0181-x

18. Rowntree GWG, Stokes AD (1994) Fire ignition by aluminum particles of controlled size. J Electr Electron Eng Aust 14(2):117-123

19. Stokes AD (1990) Fire ignition by copper particles of controlled size. J Electr Electron Eng Aust 10(3):188-194

20. Gol'dshleger UI, Barzykin VV, Ivleva TP (1973) Ignition of condensed explosives by a hot spherical object. Combust Explos Shock Waves 9(5):642-647

21. Urban JL, Zak CD, Fernandez-Pello C (2014) Cellulose spot fire ignition by hot metal particles. Proc Comb Inst. doi:10.1016/j.proci.2014.05.081

22. Zak CD, Urban JL, Fernandez-Pello C (2014) Characterizing the flaming ignition of cellulose fuel beds by hot steel spheres. Combust Sci Technol 186(10-11):1618-1631 
23. Manzello SL, Cleary TG, Shields JR, Maranghides A, Mell W, Yang JC (2008) Experimental investigation of firebrands: generation and ignition of fuel beds. Fire Saf $\mathbf{J}$ 43:226-233

24. Ellis PF (2000) The aerodynamic and combustion characteristics of eucalypt bark-a firebrand study, Ph.D. dissertation, Australian National University, Canberra

25. McGuire JH, Law M, Miller JE (1956) Domestic fire hazard created by flying coals and sparks (FR note 252). Fire Res Station, Borehamwood

26. Hartford RA (1989) Smoldering combustion limits in peat as influenced by moisture, mineral content, and organic bulk density. In: MacIver DC, Auld H, Whitewood R (eds) Proceedings of the 10th conference on fire and forest meteorology, April 1989, Ottawa. Forestry Canada, Petawawa National Forestry Institute, Chalk River, pp 282286

27. Grishin AM, Golovanov AN, Sukov YV, Preis YI (2006) Experimental study of peat ignition and combustion. J Eng Phys Thermophys 79(3):563-568

28. Frandsen WH (1987) The influence of moisture and mineral soil on the combustion limits of smoldering forest duff. Can J For Res 17:1540-1544

29. Frandsen WH (1997) Ignition probability of organic soils. Can J For Res 27:1471-1477

30. Rittel D, Osovski S (2010) Dynamic failure by adiabatic shear banding. Int J Fract 162(1-2):177-185

31. Incropera FP, DeWitt DP (2002) Introduction to heat transfer. Wiley, New York

32. Churchill SW, Bernstein M (1977) A correlating equation for forced convection from gases and liquids to a circular cylinder in crossflow. ASME Trans J Heat Transf 99:300-306

33. Finney MA, Maynard TB, McAllister SS, Grob IJ (2013) A study of ignition by rifle bullets. Res Pap RMRS-RP-104. US Department of Agriculture, Forest Service, Rocky Mountain Research Station, Fort Collins, CO, 31p

34. Christiensen R (1998) Analysis of variance, design, and regression (Chap. 62). Bonferonni adjustments Chapman \& Hall, Boca Raton, FL

35. Abernathy JB (1968) Ballistic impact flash. Masters Thesis. School of Engineering of the Air Force Institute of Technology, Air University. Wright-Patterson Air Force Base, Ohio. 50p

36. Mansur JW (1974) Measurement of ballistic impact flash. Masters Thesis. School of Engineering of the Air Force Institute of Technology, Air University. Wright-Patterson Air Force Base, Ohio, 51p 